\title{
Inquisición y Guerra de Sucesión $(1700-1714)$
}

\author{
Mª del Pilar Domínguez Salgado
}

La llegada de los Borbones a España se asocia inmediatamente con la Guerra de Sucesión, en su doble aspecto de contienda internacional y de guerra civil. Aunque el riesgo de guerra era grande desde noviembre de 1700, hasta abril de 1701 no hubo hostilidades de ninguna clase. Durante un año combatieron en Italia franceses y austriacos, pero sólo en el verano de 1702 se generalizó la guerra, al desembarcar los ingleses en los Países Bajos. Y aún habrían de transcurrir otros tres años, hasta que se introdujese la contienda civil en España, con el levantamiento de valencianos y catalanes a favor del archiduque Carlos de Austria. Hasta entonces, es decir, hasta el verano de 1705, con el entusiasmo de unos y con la apatía o aversión secreta de otros, Felipe $\mathrm{V}$ había reinado sin oposición.

Al principio de la guerra (1702), el rey salió hacia Italia, dejando a la reina como gobernadora, con una Junta de Estado presidida por el cardenal Portocarrero. Mientras duró la contienda, puede decirse que la dirección de los asuntos políticos interiores y exteriores de España estuvieron a cargo de la reina, que para ello contó con dos excelentes auxiliares en las personas de los franceses Orry y Amelot. Ambos reorganizaron la Hacienda española, e introdujeron en España el sistema de las Intendencias.

En 1701, Felipe $V$ regresó a España. Durante dicho año, sólo se registraron combates de alguna intensidad en la frontera portuguesa, pero en previsión de sucesivos incidentes entraron en suelo español numerosas tropas francesas, a la par que la administración dura y eficiente de Orry, preparaba la movilización de los recursos del país '.

. Dominguez Ortiz, A., Sociedad y Estado en el siglo xVIII español. Barcelona. Ariel. 1984. 


\section{PRIMERAS PROPUESTAS DEL SANTO OFICIO AL NUEVO MONARCA}

Las reformas administrativas de Felipe $\mathrm{V}$ no disminuyeron los privilegios de la Inquisición. A pesar de ello, el 30 de julio de 1704, el Consejo de Inquisición le presentó un memorial, en donde manifestaba su falta de recursos económicos, así como la de los distintos tribunales inquisitoriales; asimismo, solicitaban que se formase una "Junta de Ministros" para que, analizando su situación, aportase soluciones a la misma, sin resultar gravosas a la también maltrecha economía real.

En respuesta a esta solicitud, el monarca les propuso que fueran ellos mismos quienes aportasen las posibles soluciones, a la vez que requeria información, sobre como se administraban los recursos económicos de la institución inquisitorial.

En contestación a los requerimientos del rey, el Consejo de Inquisición elaboró un informe que presentó a Felipe $\mathrm{V}$, en el que se alegaba que las "confiscaciones de bienes" habían faltado desde hacía "algunos años a esta parte» debido a la «cautela y astucia de los judíos» que vivían temerosos de ser apresados por el Santo Oficio. Por lo que no les quedaban más rentas que las eclesiásticas (canongías, curatos, subsidios de los obispados...etc.) y algunos juros y censos (que habian dejado de pagarse a causa de la guerra, siendo, tras ella, las sumas tan elevadas que los contribuyentes no podían pagarlas). En cuanto a las «Penas y Penitencias", el Consejo las consideraba de poca utilidad, dado que eran de escasa importancia las "multas pecuniarias" que se imponían a los reos en la determinación de las causas (las "penas y penitencias" eran multas o sanciones económicas que el Santo Oficio imponía a ciertos reos por diferentes motivos, recurriendo a este tipo de ingresos cuando el tribunal se encontraba falto de recursos) ${ }^{2}$.

Así pues, por todo lo anterior, el Consejo de Inquisición proponía que el remedio más eficaz para paliar su delicada situación económica, era eliminar todos los gastos que fueran superfluos, reduciéndolos a los indispensables y necesarios para el «servicio de este Santo ministerio, conforme a la ocurrencia de negocios que ordinariamente se ofrecen en cada tribunal», reduciendo, en algunos, el número de inquisidores y ministros, tal y como lo propuso en su Reforma el Inquisidor General Sarmiento de

2 AHN, Inquisición, leg. 3.583, caja 2ª , exp. 38. MARTínez MILLÁ, J., La Hacienda de la Inquisición (1478-1700). Madrid, 1984, págs. 75 y 76. 
Valladares, el año 1677. De esta forma, el Consejo, entre otras cosas, propuso al rey lo siguiente:

a) Que se eliminase, según quedasen vacantes, las plazas del Consejo, hasta que quedasen en el número de cinco, más la que estaba concedida a la orden de Santo Domingo y las dos que servían en él los dos consejeros de Castilla (en total ocho consejeros), que era lo que proponía la antigua reforma de Sarmiento de Valladares.

b) Que cuando llegase el caso de quedar vacante el oficio de oficial mayor de la Contaduría General, y el de Depositario General del mismo Consejo, cesasen los sobresueldos o ayudas de costa vitalicias que, con anterioridad, habían concedido los Inquisidores Generales a los que servían estos dos oficios. Y a la persona que fuese nombrada para la plaza de oficial mayor de la Contaduría General entrase sólo con el goce del salario, propinas, casa de aposento...Y que la plaza del Depositario General llevase el salario de 500 ducados de vellón.

En cuanto a los tribunales del Santo Oficio, propusieron lo siguiente:

a) "Que en la Inquisición de Corte haya sólo un inquisidor y tres secretarios y no se provea la plaza de inquisidor que sólo para los muchos negocios de Hacienda, que entonces estaba pendiente, creó el Inquisidor General Sarmiento de Valladares, porque habiéndose concluido todo mucho tiempo ha, y no ofreciéndose otros, cesa el único motivo de esta temporal providencia. $Y$ que respecto de haber continuado, en virtud de especial orden del obispo de Segovia, Inquisidor General, en el ejercicio de la plaza de Inquisidor el obispo de Santa Fe, después de su consagración, sin ejemplar en el Consejo, ni tribunales del Santo Oficio, cese en él desde luego, pues no es justo que goce sin necesidad a un mismo tiempo de las dos rentas de su arzobispado y de la plaza de Inquisidor. Y que así mismo se resuma, pues tampoco es necesario, el oficio de oficial de la secretaría de secuestro en la primera vacante».

b) Que para conseguir el efecto deseado por la Reforma se proponía que las plazas vacantes de inquisidores y secretarios, en los tribunales de Castilla y Aragón, fuesen cubiertas mediante traslado de inquisidores y secretarios de otros tribunales del Santo Oficio, procurando en sus promociones la mayor conveniencia tanto para el ministro trasladado como para aquellas inquisiciones que tuviesen más necesidad de personal. Sin que los Inquisidores Generales pudiesen nombrar "personas de fuera", es decir, otorgar nuevos nombramientos, hasta que se consiguiese la reducción de plazas que exigía la Reforma. 
c) Que cuando en alguno o algunos tribunales ocurriese algún conflicto, antes o después de reducirse el número de inquisidores y secretarios, según lo que proponía la Reforma, y no bastando para la resolución del conflicto con el personal que existiese en el tribunal, podrían ir inquisidores y secretarios de otros tribunales para ayudarles, pagándoles el viaje y dándoles la correspondiente «ayuda de costa» (dietas). $Y$ acabándose las «causas», se restituirán a sus tribunales respectivos, como se había venido haciendo en semejantes casos.

d) Y para que se observe y guarde siempre la Reforma referida, si por algún accidente se tuviese la necesidad de exceder el número de ministros que en ella se prescriben, no puedan los Inquisidores Generales hacerlo, sin participarlo y consultarlo con el Consejo, y dar cuenta al rey de ello, antes de pasar a su resolución y que lo mismo se hiciese cuando, por algún motivo, pareciese conveniente aumentar el salario de algunos oficios, esperando en este caso la resolución del rey $^{3}$.

De esta forma, observamos que a partir de 1704 en el tribunal de Corte sólo ejercerá un Inquisidor, pues en la Reforma administrativa que proponía el Consejo, se eliminaba la figura del Inquisidor Ordinario para Asuntos de Hacienda creado por Sarmiento de Valladares. Al llegar a este punto, nos podemos preguntar ¿qué ocurrió con la «reforma» presentada por este Inquisidor General y aprobada por Carlos II? Las respuestas pueden ser diversas; una de ellas sería que dieron un margen de tiempo, tanto al Consejo como a los tribunales, para la nueva reorganización en cuanto al número de funcionarios; y otra sería que, a pesar de las buenas intenciones de Sarmiento de Valladares, la reforma no se llevó a efecto debido, principalmente, a causas económicas, porque la persecución de los conversos, con el consiguiente secuestro de bienes, colmaron las arcas de los tribunales y del propio Consejo y, por lo tanto, no pudieron prescindir del personal que aconsejaba el Inquisidor General.

Pero, a principios del siglo xVIII, las persecuciones habian terminado, y el Consejo y tribunales inquisitoriales atravesaban un «bache» en sus finanzas, lo que motivó el Memorial presentado al monarca, al que se le recordaba de pasada que se le siguieran manteniendo ciertos privilegios como antaño gozaba la Institución Inquisitorial.

3 AHN, Inquisición, leg. 3.583 , caja $2^{2}$. 
Así, a partir de 1704, será cuando la reforma propuesta por Sarmiento de Valladares en 1677, entrará en vigor con todas sus consecuencias. Por otra parte, en 1706 el monarca dio un decreto para que se le hiciera una Relación, en la que se le informase del número de ministros que existían en los tribunales, así como de sus títulos, edades, lugares de origen y el tiempo que habían ocupado la plaza en su correspondiente tribunal ${ }^{4}$.

De lo anteriormente expuesto se puede deducir una pérdida de poder de la figura del Inquisidor General, ya que no podrá tomar decisiones de carácter económico (que a fin de cuentas condicionan el resto de las actuaciones del Santo Oficio) sin contar con el beneplácito del máximo órgano colegiado de la Institución y de la voluntad del soberano, el cual, vigilando de esta forma la hacienda de la Inquisición, controlará sus influencias ideológicas y políticas, pudiendo utilizarla para sus propios fines.

De esta forma aparece una institución supeditada y manejada por el rey, formando un todo con la Corona. Atrás quedaba la antigua independencia de la Inquisición; desde ese momento será un instrumento político en manos del monarca.

\section{CONSECUENCIAS DE LA GUERRA EN LA VILLA DE MADRID}

Desde el principio de la guerra, el rey y la Corte se trasladaron a Burgos. En 1706, el archiduque entró en la capital y recogió la adhesión de no pocos nobles y funcionarios, pero el recién titulado Carlos III no sólo se dio cuenta de la frialdad con que le acogieron los madrileños, sino de lo delicado de su situación en medio de un país enemigo. Todas las provincias castellanas reclutaban nuevas tropas, y partidas sueltas hostigaban a las aliadas hasta las puertas de la capital, por lo que el archiduque decidió abandonar ésta y retirarse hacia Levante ${ }^{5}$.

En la primera ocupación de Madrid por "Carlos III" parte de los miembros del Consejo y del Tribunal de Corte permanecieron en la capital, y fueron informando al Inquisidor General de los sucesos que se iban desarrollando en la villa.

Ibidem, leg. 2.508, exp. 9.

5 Domínguez Ortiz, A., Sociedad y Estado.., op. cit. 
A partir del 23 de junio de 1706 la correspondencia entre José de la Cana ${ }^{6}$ y Antonio Álvarez de la Puente ${ }^{7}$, secretarios del Consejo, nos va dando noticias de lo que iba ocurriendo en Madrid y en sus alrededores.

En un principio se muestra la preocupación de estos ministros porque llegase a Burgos la documentación que poseía la institución en Madrid; más tarde, después de la salida del archiduque de la capital, cuando los «correos ordinarios» que, por orden de Felipe $V$, comenzaron a funcionar de nuevo, se empiezan a dar noticias de las prisiones efectuadas a los adictos al Archiduque, «siendo la última, la intentada y no conseguida, la de D. Francisco Daza, secretario de Guerra de Mar, porque le valió la diligencia que puso en ocultarse, dejando abandonada y expuesta al secuestro su casa y hacienda y se van prosiguiendo otras, de manera que ha sido preciso evacuar las cárceles y trasladar al campo muchos de los que estaban en ellas» ${ }^{8}$.

Igualmente, comentaban que la «Justicia de Madrid» andaba vigilante, con «celadores de día, con Rondas de noche, y en todo lo que obra adquiere muchos aplausos, especialmente en las prisiones de varias personas, a quienes el pueblo miraba con horror, considerándolas instrumentos del partido contrario (austriaco), y se han interesado en su prisión y en su castigo los buenos vasallos... habiendo causado no poca admiración la resolución del conde de Oropesa, de cuya comitiva se escapó el conde de Aros, que se pasó a nuestro campo" ${ }^{9}$.

6 AHN, Inquisición, leg. 2.503, exp.3; lib. 394, fol. $157 \mathrm{v}^{\circ}$ y fol. $159 \mathrm{r}^{\circ}$; lib. 1.340 , fol. $170 \mathrm{v}^{\mathrm{a}}$. A José de la Cana, el 16 de junio de 1687, Sarmiento de Valladares le concedió el título de notario del secreto del Tribunal de Corte. Antes fue notario del secreto del tribunal de Valladolid, concedido el título en 1685, sirviéndolo durante 16 meses. Valladares ordenó que se le ayudase con el mismo salario y ayuda de costa para la casa de aposento, como se daba a Felipe Antonio de la Cana, notario del secreto de la Inquisición de Sicilia que estaba sirviendo en "comisión de servicios" en el tribunal de Corte. Tenía de sueldo 500 reales y "consignados» 200 ducados de plata en la Inquisición de Lima. En 1707 era secretario del rey y oficial mayor de la secretaría del Consejo, "por lo tocante a la corona de Castilla y León". Vecino y natural de la villa de Madrid, pariente de Felipe Antonio de la Cana; cuñado de Antonio Álvarez de la Puente y Cienfuegos y tío de Antonio Álvarez de la Puente y Cana; padre de José de la Cana Ochoa y Tejada.

7 Ibidem, lib. 396, fol. 200 ro; lib. 403, fol. 173 ro; lib. 645, fol. 32 ro; lib. 1.340, fol. $171 r^{\circ}$ y fol. 189 $\mathrm{r}^{\mathrm{o}}$; lib. 484, fol. $218 \mathrm{r}^{\circ}$. A Antonio Álvarez de la Puente y Cana, el 28 de junio de 1698 , el Inquisidor General Rocaberti le concedió el título de notario del secreto del Tribunal de Corte. Con anterioridad habia sido nombrado secretario del secreto de la inquisición de Murcia con asistencia en el Tribunal de Corte el 11 de agosto de 1694. Gozaba como secretario más antiguo del Tribunal de la «casa de aposento". El 25 de enero de 1707 fue nombrado oficial mayor de la secretaría de Aragón del Consejo. Fue caballero de la orden de Santiago. Hijo de Antonio Álvarez de la Puente y Cienfuegos, secretario del secreto del tribunal de Corte y de Josefa de la Cana, hermana de José de la Cana, ambos hijos de Mateo de la Cana y de Juana Calvo; primo de José de la Cana Ochoa y Tejada.

s Ibidem, leg. 2.506, exp. 9.

9 lbidem. 
Aparte de las noticias sobre el desarrollo de la guerra en los alrededores de Madrid, daban también una relación de los personajes que se apresaron en la capital, cabe señalar al marqués de Aravaca y su hijo; a Gregorio Mella, del Consejo de Guerra; a Antonio Ibáñez de Bustamante, con secuestro de bienes; a Juan de Lavia, relator del Consejo de Indias; a Tomás de Suazo, escribano de cámara del Consejo Real; y a José Niño, corregidor de Toledo, nombrado por el archiduque. Además de los citados personajes, se detuvieron a más de cien personas, así eclesiásticas como seculares, y de los conventos de Madrid se echaron a muchos religiosos, quedando otros recluidos en sus celdas. También remitieron una relación de las personas que se buscaban para prenderlas y que, ante su huida, a unos se les secuestraron sus bienes, y a otros se les saquearon sus pertenencias:

- Conde de San Pedro: secuestro.

- D. Juan Crisóstomo de la Pradilla: saqueo.

- D. Juan de Casno Gallego: saqueo.

- D. Juan de Sesma, contador de Relaciones: secuestro.

- D. Francisco de Ocio, escribano mayor de Rentas: secuestro.

- D. Pascual de Quiñones: secuestro ${ }^{10}$.

Nuevamente, en septiembre de 1706, se volvieron a cerrar los correos ordinarios, quedando incomunicada la capital con el resto de la Corte. Ante esta situación, el Inquisidor General envió al Tribunal de Corte y a sus ministros la orden de que upara seguir la correspondencia conmigo y con el Consejo... se continuarán remitiendo los procesos y papeles...en la misma conformidad que antes se hacía.» ${ }^{11}$.

Alrededor del 18 de agosto de 1706 se rumoreaba que Felipe $V$ daría orden para que los consejos se fueran restituyendo a la Villa «que desde que dejó de ser Corte de su dueño y pasó a serlo del que no lo es, ha parecido la quimera de este siglo, viéndose en ella lo que dificultosamente cupiera en el dilatado campo de la posibilidad y de una monstruosa agitación de apresos militares y políticos, ha venido a una total calma de negocios, porque cerrados y suspendidos los tribunales de ninguno se trata, quedando reducido su gobierno al de la Justicia ordinaria, como en otro cualquiera de los lugares del reino.» ${ }^{12}$.

El 27 de septiembre de 1706, el Consejo de Inquisición ya se encontraba en Madrid, y nada más llegar a la capital comenzaron las «purgas

\footnotetext{
10 Ibidem.

11 Ibidem, lib. 412 , fol. 75 ro

12 Ibidem, leg. 2.506, exp. 9.
} 
políticas" con las prisiones de diferentes ministros del Santo Oficio; el obispo de Ceuta e Inquisidor General, dio comisión al Ldo. Juan García de Ovalle Arias Maldonado, inquisidor de Toledo, que residía en la Corte, para que cumpliendo lo ordenado por el rey en su real decreto de 23 de septiembre de 1706, recibiese información para averiguar si Alonso de Navia Bolaños y Domingo de Pernas y Modia, ambos consiliarios y demás ministros del Consejo, habían incurrido en las culpas que se expresaban en el real decreto.

Los ministros que resultaron "culpables» de traición fueron: el secretario del Consejo, Francisco de la Maza y Prada; Martín de Aguirre, alguacil mayor del Consejo; Marcos Marañón y Andrés Francisco de Anatave, relatores del mismo; Alonso Pérez de Almansa, receptor general; Rodrigo de Encinas, contador general (en ausencias y enfermedades); Fernando Pando, agente fiscal del Consejo; Miguel López de Sobrado, depositario; Juan Docampo, depositario de pretendientes a Indias; Ambrosio Serrano, oficial del Registro de la secretaría de Castilla; Juan Escaldo, oficial de dicho Registro, ya jubilado; Jaime Ruíz de Castilblanque, capellán del Consejo y Juan Antonio de Pravia, portero jubilado ${ }^{13}$.

De todos ellos hay constancia de que fueron condenados: Juan de Escaldo Pinilla, que en 1668 había sido nombrado por Nithard contador del Despacho de Corte ${ }^{14}$, y que en ese momento era oficial de la secretaría del reino de Castilla, cuya prisión se ejecutó quedando preso en su casa, con una guardia a causa de sus enfermedades; a Francisco Rubio, nuncio del Consejo, se le llevó preso a las cárceles de Familiares y se le embargaron sus bienes; a Juan Antonio de Pravia, aunque se le buscó, no se le pudo prender por encontrarse fuera de Madrid; y a Marcos Marañón, relator del Consejo, a quien se le notificó que se quedase preso en su casa, con multa de 1.000 ducados si lo quebrantaba ${ }^{15}$.

También por estas fechas, en noviembre de 1706, comenzó una férrea censura política sobre todas las obras que salieron a favor del archiduque; una de ellas, tifulada el Anónimo, motivó que el Santo Oficio hiciese averiguaciones sobre su autor, el cual pareció ser el propio D. Carlos de Austria ${ }^{16}$; si en la nobleza se observaron divisiones internas a favor o en contra de Felipe $V$, iguales divisiones se registraron en las filas del clero, que vivió el drama de la guerra con gran intensidad. El altar, el

13 Ibidem, leg. 2.511, exp. 4.

14 Ibidem, leg. 2.502, exp. 3.

15 Ibidem, leg. 2.506, exp. 4.

16 Ibidem, exp. 5. 
púlpito y el confesionario se utilizaron como armas de propaganda a favor de Felipe V. Los cardenales Portocarrero, Belluga, y el obispo de Córdoba reclutaron escuadrones y regimientos a favor del duque de Anjou. $Y$ no menos pasión mostraron los eclesiásticos partidarios del archiduque, cuando entró en Madrid. Un fraile victorio (Gaspar Sánchez, que luego murió en estrechísima prisión) levantó partidas a su favor. Al recuperar la capital Felipe $\mathrm{V}$ prendió o desterró al patriarca de las Indias y a otros personajes de menor importancia. En las órdenes religiosas se produjeron graves discordias internas, y como, en realidad, ninguno de los dos bandos en lucha era enemigo de la Iglesia, lo que demuestran estos episodios era la identificación del clero español con sus compatriotas, cuyos intereses, sentimientos y rivalidades compartían ${ }^{17}$.

\section{JUECES ORDINARIOS EN EL TRIBUNAL DE CORTE}

Cuando la Corte nuevamente se instaló en Madrid, todos los organismos del Estado comenzaron de nuevo a funcionar. Así, en el Tribunal del Santo Oficio de la Inquisición de Corte, a pesar de suprimirse la figura del Inquisidor para Asuntos de Hacienda, se introdujo una nueva figura, que con anterioridad habia existido ya en los demás tribunales inquisitoriales, el Inquisidor Ordinario con poder del Azobispado de Toledo para los asuntos de fe, también llamado Juez Ordinario.

Estos nuevos inquisidores aparecieron oficialmente en el Tribunal de Corte, el 14 de marzo de 1707, con el juramento de dicho oficio del Dr. Manuel Menchero y Rozas, vicario de la Villa de Madrid ${ }^{18}$. Fueron introducidos por D. Luis Manuel, obispo de Palestina, más conocido como cardenal Portocarrero, arzobispo de Toledo, quien les dio «poder bastante» para que por «nos y en nuestro nombre y representando nuestra dicha persona, juntamente con los Srs. Inquisidores apostólicos" pudiesen "oír, conocer, decidir y determinar todas las causas y negocios que se ofrecieren en el Tribunal de Corte» ${ }^{19}$.

Esta nueva modalidad no agradó a los inquisidores de Corte, por creer que la jurisidicción eclesiástica intervenía en «terreno propio», y pronto comenzaron las desavenencias. Así, el 17 de enero de 1708, el Consejo tuvo que dar un decreto para que este nuevo ministro fuese aceptado por el resto de los ministros del Tribunal.

\footnotetext{
Domínguez Ortiz, A., Sociedad y Estado..., op. cit.

AHN, Inquisición, lib. 645 , fol. 45 .

Ibidem, fol. $44 v^{\circ} \mathrm{y}$ fol. 47 ro.
} 
«Aunque por ley real está dispuesto que la prevención real prevalezca a la verdad, y conveniendo evitar los fraudes que los ministros suelen hacer huyendo del juez que temen, le ha de castigar su delito, ha parecido al Ilmo. Sr. Obispo de Ceuta, Inquisidor General, y al Consejo, ordenaros que si los ordinarios eclesiásticos previnieron la causa con citación, se les deje conocimiento de ellas, en los casos en que por la carta acordada del 28 de noviembre de 1612, deben conocer a prevención con el Tribunal. Y que así mismo se proceda por él en la que hubiere hecho la referida citación, antes que los ordinarios, de manera que ésta tenga fuerza de prevención real, conque se mantendrá la buena correspondencia entre ambas jurisdicciones y de esta nueva disposición daréis noticia a todos los obispos de vuestro distrito para que lo tengan entendido y por su parte se practique en los casos que se ofrezcan” ${ }^{20}$.

El decreto fue enviado al inquisidor de Corte, Ramos Escajadillo, y al cardenal arzobispo de Toledo y a su vicario de Madrid ${ }^{21}$.

A pesar del decreto, los Ilamados Jueces Ordinarios siguieron no siendo aceptados, y a lo largo de todo el siglo XVIII continuaron las disputas jurisdiccionales entre el arzobispado de Toledo y la Inquisición de Corte ${ }^{22}$.

En otros tribunales, a partir de 1612, se introdujeron estos Jueces Ordinarios con competencia en todas las causas, sufriendo profundas desavenencias entre ellos, dando lugar a conflictos de competencias entre ambas instituciones (la eclesiástica y la inquisitorial). El Tribunal de Corte no tuvo ministro de este rango hasta 1707, pues aunque venía funcionando desde 1628, no se le consideró nunca como un tribunal independiente, sino como una prolongación del Tribunal de Toledo, y como tal, el vicario de Madrid actuó junto con los inquisidores de Toledo, en algunas causas de fe remitidas a éstos por los inquisidores de Corte. Pero, a partir de 1707, debido sobre todo a las persecuciones de los disidentes a la Corona, el Tribunal había adquirido un cierto prestigio iniciando, nuevamente, los intentos de independencia del tribunal de Toledo, a la vez que comenzaban a considerarle los demás tribunales y la propia jurisdicción eclesiástica como una nueva institución inquisitorial. Fue por eso por lo que el arzobispo de Toledo, aprovechando la carta acordada del 28 de noviembre de 1612, introdujo la figura del inquisidor o Juez Ordinario.

"Por cuanto para la expedición y despacho de las causas y negocios tocantes y pertenecientes a los vecinos y súbditos de este nuesto arzobispado

\footnotetext{
20 Ibidem, lib. 503 , fol. 10.

21 Ibidem.

$22 \quad$ Ibidem, leg. 2.523, exp. 7.
} 
de Toledo, que se traten y siguen en el Tribunal del Santo Oficio de la Inquisición de Corte de esta villa de Madrid, es necesario por nos y en nuestro nombre haya persona que asista juntamente con los Srs. Inquisidores Apostólicos de élla, la cual con nuestro poder...se halle haber y determinar las causas que así de derecho como de estilo y costumbre se suele hayar el Arzobispado de Toledo..." 23 .

Siguiendo un orden cronológico, citaremos a los primeros Inquisidores o Jueces Ordinarios que obtuvieron dicha plaza en el Tribunal de Corte; a partir de ellos se sucederán en dicho cargo casi todos los vicarios que tuvo Madrid, pero al no pertenecer propiamente a la Inquisición, y ser mínima su aportación en el funcionamiento del tribunal, omitiremos los restantes.

\section{MENCHERO Y ROZAS, MANUEL:}

Vicario "de esta Villa", natural de la ciudad de Santa Cruz de Mudela (arzobispado de Toledo). El 14 de marzo de 1707 juró, ante el inquisidor Gregorio Ramos Escajadillo y Posada, el oficio de inquisidor ordinario con el «poder del cardenal Portocarrero", ${ }^{24}$.

\section{GIL TABOADA, Padre FELIPE ANTONIO:}

El 24 de septiembre de 1709 se le concedió «poder» por el cabildo de Toledo para ejercer como Ordinario. Canónigo de Toledo, vicario de Madrid. colegial de Fonseca. Natural del lugar de Bergazos, Iglesia de Santa Eulalia de Donjun, jurisdicción de Deza, obispado de Lugo. Catedrático de Prima de Leyes en la universidad de Santiago. El 4 de noviembre de 1709, ante el inquisidor Santiago Hidalgo, juró su oficio para asistir como Inquisidor Ordinario en la Inquisición de Corte, siendo admitido al ejercicio de Juez Ordinario ${ }^{25}$.

\section{Ramírez de la Piscina, Francisco:}

Título de Inquisidor Ordinario del tribunal de Corte, nombrado por Francisco Judice, el 15 de abril de 1712; presbítero, ascendió a Consiliario el

23 Ibidem, lib. 645 , fol. $44 \mathrm{v}^{\mathrm{0}}$ y fol. $47 \mathrm{r}^{\circ}$,

24 Ibidem, fol. 45 .

25 ibidem, fol. 67. 
6 de febrero de 1713. Natural de la villa de Ávalos (Obispado de Calahorra), arcediano de Alcaraz, dignidad y canónigo de la catedral de Toledo, vicario de Madrid el 10 de febrero de 1712. Falleció en agosto de $1724{ }^{26}$.

Álvarez de Peralta, Nicolás:

El 1 de septiembre de 1717 juró su oficio de Juez Ordinario. Vicario de Madrid; licenciado ${ }^{27}$.

\section{NUEVO INTENTO DE INDEPENDENCIA DEL TRIBUNAL DE CORTE}

En 1708, los ministros del tribunal de Corte elevaron sus quejas al Consejo de Inquisición en un memorial donde informaban del mal trato que recibían por parte del Santo Oficio de Toledo, quien seguía considerando como prolongación suya al tribunal de Corte, con las diferentes repercusiones que esto traía a los funcionarios del Tribunal.

El conflicto surgió cuando los secretarios de la inquisición de Toledo llegaron a Madrid para realizar las averiguaciones de «limpieza de sangre» de los pretendientes a oficiales del Santo Oficio, que eran naturales o vecinos de la Villa de Madrid, con el consiguiente perjuicio para los secretarios del tribunal de Corte y para los propios interesados (por el tiempo que se tardaba en realizar las pruebas, como por los gastos que se ocasionaban). Este problema se venía repitiendo desde hacía tiempo, sin que consiguieran ponerse de acuerdo, en cuanto a sus propias jurisdicciones, los secretarios de ambos tribunales.

En el memorial enviado al Consejo se recordaba al Inquisidor General que, por el año 1703, se había producido una circunstancia similar o de parecidas características, al remitir la inquisición de Toledo a la de Corte un «mandamiento de ejecución» contra los bienes de la condesa de Villaverde, para que se ejecutara. Por este asunto el tribunal de Corte recurrió al Inquisidor General, protestando porque el «mandamiento" no había llegado con la cortesía acostumbrada, como lo hacían otros tribunales del Santo Oficio; suplicando al Inquisidor General que actuase de forma pertinente ante la situación creada, llamando la atención al tribunal de Toledo para tratar de evitar los conflictos que venían padeciendo

\footnotetext{
$197 v^{\circ}$. 27 Ibidem, lib. 645 , fol. 88 ํo.
}

26 Ibidem, lib. 418 , fol. 30 r $^{\circ}$; lib. 645 , fol. $52 v^{\mathrm{a}}$ y fol. $53 \mathrm{r}^{\circ}$; lib. 1.201 , fol. 173 ro. lib. 1.340 , fol. 
ambos tribunales. Pero el Inquisidor General optó por una solución "salomónica», aconsejando al Inquisidor de Corte «sin perjuicio de su derecho", que realizase lo que le ordenaba Toledo y que se escribiese a este tribunal para evitar en adelante «las repetidas dudas y controversias que se ofrecen cada día entre él y el despacho de Corte", solicitando además del tribunal de Toledo, un informe detallado donde explicase qué motivaciones tenía para tratar así al de Corte. El inquisidor de Corte, ante la decisión de Mendoza y Sandoval, ejecutó lo ordenado, escribiendo al santo oficio de Toledo para que éste expusiese sus «razones y fundamentos», sin que el tribunal diese ninguna respuesta al respecto, siguiendo así, durante años, los roces, tensiones y malentendidos entre ambos tribunales.

De esta forma, viendo que al cabo de tanto tiempo los inquisidores de Toledo seguían sin conceder una respuesta a las quejas de los de Corte, y que continuaban las disputas entre ellos por cualquier motivo, los ministros del Tribunal de Corte decidieron no esperar más una explicación por parte del Santo Oficio de Toledo, enviando el 16 de abril de 1708 un informe, donde exponían detalladamente sus razones para que el inquisidor General y el Consejo decidiesen al respecto. El informe o memorial argumentaba lo siguiente:

1) Que coincidiendo los diferentes inquisidores generales y el Consejo supremo de la Inquisición en la necesidad de crear un tribunal que controlase la Corte, en vez de ser tratados sus asuntos por un comisario, decidieron establecerlo con las mismas facultades que el resto de los tribunales del Santo Oficio. Dando el primer paso, el Inquisidor General Diego de Arce y Reinoso, obispo de Plasencia, quien compró las casas que «actualmente» tenía su sede la Inquisición de Corte, además de otras adquiridas posteriormente para ejercer mejor sus funciones.

2) Que a pesar de cometer algunos errores en sus comienzos, dado el carácter experimental del nuevo organismo inquisitorial, se fueron subsanando con el paso del tiempo, asemejando su funcionamiento al resto de los tribunales del Santo Oficio, ${ }^{28}$.

Además, Gregorio Ramos Escajadillo, inquisidor de Corte ${ }^{29}$, opinaba que Toledo no tenía motivos suficientes, para seguir negando la inde-

28 Ibidem, lib. 503 , fol. 163 y ss.

29 Ibiem, lib. 407; lib. 413, fol. 111 vo. Gregorio Ramos Escajadillo fue nombrado por Baltasar de Mendoza y Sandoval, el 21 de octubre de 1702, Inquisidor Ordinario del Tribunal de Corte para los asuntos de Hacienda. Presbítero; inquisidor apostólico de Valladolid; ascendió como consiliario al Consejo de Inquisición el 18 de abril de 1708. 
pendencia de la Inquisición de Corte, justificando su razonamiento de la siguiente manera:

- Los Inquisidores Generales y el Consejo en sede vacante expedían los títulos y nombramientos con independencia, pues ellos mismos decían: «...os creamos y diputamos a vos fulano que habéis sido ministro de tal Inquisición, por Inquisidor o Secretario de la de Corte», así como se acostumbra en los "despachos» que se daban para otras Inquisiciones, cuando era promovido algún funcionario de un tribunal a otro. Pero si las razones expuestas no bastaban para justificar la independencia del Tribunal de Corte del de Toledo, Ramos Escajadillo especificaba que tanto en las causas de fe, como en los pleitos, "ratificaciones, defensas, recorrección de registros», toda clase de delitos, edictos de prohibición de libros, y demás papeles, iban refrendados por la Inquisición de Corte, e igualmente, los Inquisidores Generales y el Consejo les enviaban como a un tribunal más, y con el mismo tratamiento las "cartas acordadas".

Por otra parte, considerando el Inquisidor la posibilidad de que el tribunal de Toledo consiguiese la jurisdicción sobre Madrid, se quejaba de que en tal caso, los funcionarios del de Corte residentes allí, no iban a ser considerados por los de Toledo compañeros suyos, según el rango y el grado, sino subalternos $y$, por consiguiente, no iban a poder entrar en el turno y lugar que a cada uno le correspondiese en todos los asuntos o papeleos de limpieza de sangre que existieran en la Villa, convirtiéndose así, el Tribunal del Corte, en el que ejecutase todo el trabajo, llevándose los laureles y las compensaciones el de Toledo, como ya lo habían intentado en tiempos pasados. De esta forma, Ramos Escajadillo, solicitaba del Consejo una declaración sobre la independencia del Tribunal de Corte con respecto al de Toledo, especificando que ésta no debía ser en beneficio o en interés particular de los ministros que la solicitaban, sino que era precisa y necesaria para eliminar de una vez para siempre todos los inconvenientes que ocasionaban estas diferencias entre ambos tribunales ${ }^{30}$.

Ante las razones expuestas por el Inquisidor de Corte, el Consejo ordenó al tribunal de Toledo que explicase los motivos que tenía para no acceder a la pretensión del de Corte, pero el Santo Oficio de Toledo siguió callando su respuesta, como lo hizo igualmente ante otro memorial presentado por los ministros del de Corte al Consejo, en 1712. A pesar de todos estos hechos, el Consejo no se decidió a realizar una proclamación oficial sobre la independencia del Tribunal de Corte, aunque en la práctica le considerase como tal.

3o Ibidem, lib. 503 , fol. 163 y ss. 
Los diferentes intentos del Tribunal de Corte por lograr su independencia habian chocado con problemas de índole diversa. Años atrás, en 1698, el tribunal se encontraba con una Corte dividida en dos bandos, preocupada por el problema sucesorio de Carlos II; se daba la circunstancia de que el bando que más adictos tenía era el pro-francés, capitaneado por el cardenal Portocarrero, arzobispo de Toledo, con gran poder sobre la mayoría de las instituciones estatales, entre ellas el Consejo de Inquisición, y que por las razones que fuesen, no veía con buenos ojos la independencia del Tribunal de Corte, ${ }^{31}$; en 1703, gobernaba la Inquisición Mendoza y Sandoval, pro-austriaco, y en la Corte existía un ambiente de guerra a punto de estallar; en los siguientes años, 1708 y 1712, se encontraban en plena Guerra de Sucesión, teniendo, además, sobre sí la privanza de Macanaz, quien trataba de recortar poder y privilegios a la Institución. Así pues, hasta 1750 no se darán una serie de circunstancias favorables para que las aspiraciones del Tribunal de Corte triunfasen, como así sucedió con el «Estatuto» de 1752, ${ }^{32}$.

31 Ibidem, leg. 2.500, exp. 9; para más información sobre el tema, véase: Domínguez SaLGado, P., «inquisidores y Fiscales del Tribunai de Corte (1580-1700)», Revista de la Inquisición (en prensa).

32 Domínguez Salgado, P., «Estatuto» del Tribunal de Corte (1752)», Anales del Instituto de Estudios Madrileños, 34, Madrid, 1954, págs. 415-426. 